\title{
Implementasi Metode GRAND MBA Guna Memberantas Buta Huruf Al-Qur'an
}

\author{
${ }^{1 *}$ Muhamad Apep Mustofa, ${ }^{2}$ Rahmat Fitriansyah, ${ }^{3}$ Ade Rijal Jaelani, ${ }^{4}$ M Imron Hamzah, \\ ${ }^{5}$ Abdul Haris, 6 Nurjaya \\ 1.2.3.4.5STIE Hidayatullah Depok, Depok, Jawa Barat, Indonesia \\ ${ }^{6}$ Universitas Suryakancana, Cianjur, Jawa barat, Indonesia \\ *apep@stiehidayatullah.ac.id
}

\begin{abstract}
Abstrak
Tujuan pengabdian kepada masyarakat (PKM) ini adalah untuk membrantas baca tulis alqur'an terutama anak-anak yang mana hal tersebut sejalan dengan program pemerintah kota Depok. Pemberantansan baca tulis al-qur'an ini dilakukan di masjid guna mendekatkan hati anak-anak pada sarana ibadah (masjid) sehingga masjid tidak hanya dipandang sebagai sarana ibadah ritual saja, akan tetapi sebagi sarana edukasi. Metode yang digunakan dalam kegiatan ini adalah GRAND MBA (Gerakan Nasional Dakwah Membaca dan Belajar Al Qur'an) dengan metode ini masyarakat diantarkan untuk dapat membaca, menerjemahkan, menghafal dan mengamalkan al-qur'an dengan tepat. Selain itu kami juga mengajarkan etika dan adab di dalam masjid, sehingga kesakralan masjid sebagai sarana ibadah tetap terjaga.
\end{abstract}

Kata Kunci: Pendidikan, Teknologi

\begin{abstract}
The purpose of this community service (PKM) is to complete the reading and writing of the Koran, especially for children, which is in line with the Depok city government program. The eradication of reading and writing of the Qur'an is carried out in mosques to bring children's hearts closer to the means of worship (mosques) so that the mosque is not only seen as a means of ritual worship, but also as a means of education. The method used in this activity is the GRAND MBA (National Movementfor Da'wah Reading and Learning the Qur'an) with this method the community is brought to be able to read, translate, memorize and practice the Qur'an properly. In addition, we also teach ethics and etiquette in the mosque, so that the sacredness of the mosque as a means of worship is maintained.
\end{abstract}

Keywords: Education, Technology

\section{PENDAHULUAN}

Data dari Dinas Pendidikan (Disdik) Kota Depok tercatat sebanyak 20 ribu dari 33 ribu lulusan SD tidak bisa membaca Al-qur'an hal tersebut menjadi keprihatinan baik instansi pemerintah maupun non perintah. Sehingga kami selaku mahasiswa turut berkontribusi dalam memberantas buta huruf Al-qur'an yang ada di kota Depok dengan harapan kota Depok menjadi kota yang relegius dan Qur'ani.

Selain masih banyak yang tidak bisa mengaji, masih banyak masyarakat yang belum bisa memahami bacaan Al-qur'an beserta arti atau maknanya. Sehingga Al-qur'an sebagai kitab suci umat islam dimana di dalamnya tedapat sumber ajaran islam yang mencakup seluruh aspek kehidupan tidak dapat tertransformasi dan terimplentasi dengan baik karena makna atau artinya tidak mereka pahami.

Oleh karena itu pada PKM kali ini, bertujuan untuk menyuluhkan atau memberikan edukasi kepada masyarakat supaya bisa membaca Al-Qur'an dan memahami arti atau makna yang terkandung dalam Al-qur'an dengan metode GRAND MBA (Gerakan Nasional Dakwah Membaca dan Belajar Al Qur'an) supaya nilai-nilai Qur'an dapat dipahami dan diimplementasikan dengan baik dan benar dalam kehidupan sehari-hari. 


\section{METODE}

Metode pelaksanaan pengabdian kepada masyarakat ini diawali dengan melakukan peninjauan lapangan dan koordinasi dengan pengurus masjid. Metode kegiatan ini adalah mengajak anak-anak sholat magrib berjamaah di masjid, kemudian setelah sholat magrib mengajar membaca Al-qur'an dengan metode GRAND MBA (Gerakan Nasional Dakwah Membaca dan Belajar Al Qur'an), selain itu kami juga mengajarkan etika di masjid, dan tatacara sholat.

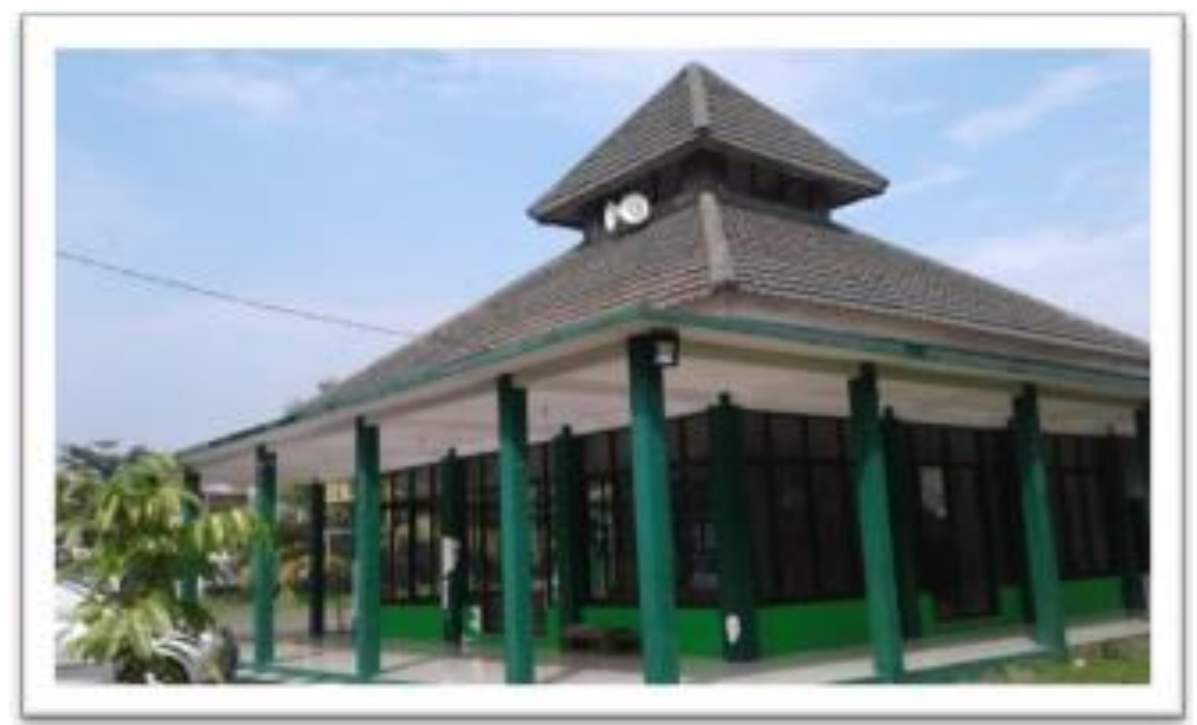

Gambar 1. Gambaran Lokasi Kegiatan PKM

\section{HASIL DAN PEMBAHASAN}

Data dari Dinas Pendidikan (Disdik) Kota Depok tercatat sebanyak 20 ribu dari 33 ribu lulusan SD tidak bisa membaca Al-qur'an hal tersebut menjadi keprihatinan baik instansi pemerintah maupun non perintah. Sehingga kami selaku mahasiswa turut berkontribusi dalam memberantas buta huruf Al-qur'an yang ada di kota Depok dengan harapan kota Depok menjadi kota yang relegius dan Qur'ani.

Selain masih banyak yang tidak bisa mengaji, masih banyak masyarakat yang belum bisa memahami bacaan Al-qur'an beserta arti atau maknanya. Sehingga Al-qur'an sebagai kitab suci umat islam dimana di dalamnya tedapat sumber ajaran islam yang mencakup seluruh aspek kehidupan tidak dapat tertransformasi dan terimplentasi dengan baik karena makna atau artinya tidak mereka pahami.

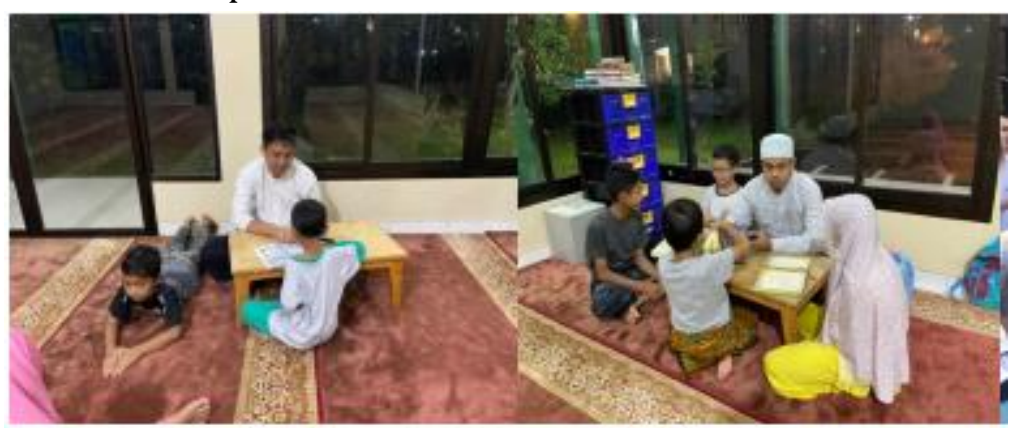

Gambar 2. Foto Akhir bersama audiens PKM

Oleh karena itu pada PKM kali ini, bertujuan untuk menyuluhkan atau memberikan edukasi kepada masyarakat supaya bisa membaca Al-Qur'an dan memahami arti atau makna yang terkandung dalam Al-qur'an dengan metode GRAND MBA (Gerakan Nasional Dakwah Membaca dan Belajar Al Qur'an) supaya nilai-nilai Qur'an dapat dipahami dan diimplementasikan dengan baik dan benar dalam kehidupan sehari-hari. 
Sentuhan para akademini memberikan sentuhan warna baru. Pembelajaran metode GRAND MBA (Gerakan Nasional Dakwah Membaca dan Belajar Al Qur'an) memberi dorongan semangat untuk mengetahui lebih banyak manfaat akan suatu Pembelajaran Al-Qur'an. Masyarakat bukan saja senang, dengan adanya pembelajaran dengan metode GRAND MBA (Gerakan Nasional Dakwah Membaca dan Belajar Al Qur'an) masyarakat merasa teredukasi dan merasa lebih dekat dengan Al-qur'an karena dengan perlahan mereka bukan hanya mampu membaca dengan baik tapi juga memahami secara perlahan isi kandungan dalam Al-qur'an.

\section{PENUTUP}

\section{KESIMPULAN}

Setelah selesai ada baiknya megulang kembali apa yang telah dipelajari dengan melibatkan peranan dan dukungan orang tua supaya materi yang diberikan dapat dipahami dan diamalkan setiap waktu, dan sebagai orang tua murid ada baiknya ibu/bapak sesekali memantau progres kegiatan belajar anak-anak di masjid.

\section{SARAN}

Saran dari kami agar pembelajaran lebih asik dikembangan menjadi sebuah kegiatan perlombaan pada perayaan hari besar islam, untuk memeriahkan hari besar islam dan memberi nilai tambah berupa kompetisi dalam hal kebaikan, karena belajar Al-qur'an membutuhkan yang relative lama.

\section{DAFTAR PUSTAKA}

Jaya, Agung Trana, (2012). Bimbingan Tahsin dan Tajwid, Jakarta: Majelis Ta'lim Hidayatullah. Jaya, Agung Trana, dkk, (2012). Buku 2 Terampil Menerjemah Al-Qur'an GRAND MBA, Jakarta: Majelis Al-Qur'an Hidayatullah (MQH)

Jaya, Agung Trana, dkk, (2012). Buku 3 Terampil Menerjemah Al-Qur'an GRAND MBA, Jakarta: Majelis Al-Qur'an Hidayatullah (MQH)

Jaya, Agung Trana, dkk, (2012). Buku 4 Terampil Menerjemah Al-Qur'an GRAND MBA, Jakarta: Majelis Al-Qur'an Hidayatullah (MQH)

Jaya, Agung Trana, dkk, (2012). Jilid 1 Terampil Menerjemah Al-Qur'an GRAND MBA, Jakarta: Majelis Al-Qur'an Hidayatullah (MQH)

Putra, IGS., et al, (2020). Dampak Pelatihan Manajemen Kreatif Industri Peci Menuju Sentra Peci Di Desa Langonsari Kecamatan Pameungpeuk Kabupaten Bandung. Coopetition: Jurnal Ilmiah Manajemen. 11(1)

Sunarsi, D. (2018). Analisis Motivasi Kerja Tenaga Pendidik Sukarela Pada Pusat Kegiatan Belajar Masyarakat (PKBM) Bimasda Kota Tangerang Selatan. Kreatif: Jurnal Ilmiah Prodi Manajemen Universitas Pamulang, 6(2), 53-65.

https://hidayatullah.or.id/read/berita-utama/2014/01/30/grand-mba-tawarkan-metodepembelajaran-al-quran-secara-tuntas/

https://www.jurnaldepok.id/2019/09/26/pemkot-depok-gerakan-magrib-mengaji/ 